\title{
Microstructural Investigations of High Productivity Au-Pd Catalysts for the Synthesis of Hydrogen Peroxide via Direct Combination of $\mathrm{H}_{2}$ and $\mathrm{O}_{2}$
}

\author{
A. A. Herzing, ${ }^{*}$ M. Watanabe, ${ }^{*}$ C.J. Kiely, ${ }^{*}$ B. E. Solsona, ${ }^{* *}$ J. Edwards, ${ }^{* *}$ P. Landon, ${ }^{* *}$ \\ A. F. Carley, ${ }^{* *}$ and G. J. Hutchings** \\ * Department of Materials Science and Engineering, Lehigh University, 5 East Packer Avenue, \\ Bethlehem, PA 18015-3195, USA
}

** Department of Chemistry, Cardiff University, P.O. Box 912, Cardiff, CF10 3TB UK

There is considerable interest in using hydrogen peroxide $\left(\mathrm{H}_{2} \mathrm{O}_{2}\right)$ as an oxygen source in the fine chemicals industry due to the environmentally benign by-product of such reactions: water. However, current production methods of $\mathrm{H}_{2} \mathrm{O}_{2}$ render it more costly than other common oxygen donors. The direct combination of $\mathrm{H}_{2}$ and $\mathrm{O}_{2}$ to form $\mathrm{H}_{2} \mathrm{O}_{2}$ is a highly desirable but difficult reaction to bring about because the reaction conditions that are required to create $\mathrm{H}_{2} \mathrm{O}_{2}$ also drive the decomposition of $\mathrm{H}_{2} \mathrm{O}_{2}$ to water. Recent work on $\mathrm{H}_{2} \mathrm{O}_{2}$ production has focused on $\mathrm{Pd}$ based catalysts operating under highly dangerous explosive conditions (elevated temperature and pressure) for hydrogen [1]. In an effort to efficiently produce $\mathrm{H}_{2} \mathrm{O}_{2}$ by direct combination of $\mathrm{H}_{2}$ and $\mathrm{O}_{2}$ in a safer manner, nanocrystals of $\mathrm{Au}, \mathrm{Pd}$, and $\mathrm{Au}-\mathrm{Pd}$ alloy were impregnated via an incipient wetness method onto $\alpha$ $\mathrm{Fe}_{2} \mathrm{O}_{3}$ particles. The catalysts were subsequently calcined in air at $400{ }^{\circ} \mathrm{C}$ and then reduced in $\mathrm{H}_{2}$ at $500{ }^{\circ} \mathrm{C}$. When catalytically tested under non-explosive conditions (low pressure, low temperature), it was found that significant $\mathrm{H}_{2} \mathrm{O}_{2}$ production was achieved when a 1:1 ratio of $\mathrm{Au}$ to $\mathrm{Pd}$ was used.

Using a VG Systems HB 603 STEM operating at $300 \mathrm{kV}$ and equipped with an XEDS detector for chemical analysis, these catalysts were investigated in order to characterize the chemical and physical nature of the metal and oxide particles. As shown in Figure 1, the metal particles exhibit a bi-modal size distribution with the larger particles typically around $30 \mathrm{~nm}$ while the smaller were less than $10 \mathrm{~nm}$ in size. STEM-XEDS mapping revealed the presence of alloy particles, since the $\mathrm{Au} \mathrm{M}_{2}$ and $\mathrm{Pd} \mathrm{L}_{1}$ signals always originated from spatially coincident areas. In order to extract more information from these maps, they were subjected to Multi-Variate Statistical Analysis (MSA), a statistical method ideally suited to analysis of spectral images of small particles [2]. Clearly, the Pd $\mathrm{L}_{1}$ (Fig. 1(b)) map suggests that the Pd is concentrated at the perimeter of the particles leaving a Aurich region (Fig. 1(c)) in the particle center.

Further evidence for this segregation effect can be seen in the HREM image shown in Figure 2 of a solitary Au-Pd particle. A slight change in contrast is observed at a radius of approximately $15 \mathrm{~nm}$ from the particle center. This most likely arises from a sudden change in composition from Au-rich in the interior to $\mathrm{Pd}$-rich at the perimeter. $\mathrm{Pd}(\mathrm{Z}=46)$ and $\mathrm{Au}(\mathrm{Z}=79)$ differ sufficiently in atomic mass that a region containing more $\mathrm{Au}$ would appear slightly darker than a region that was rich in $\mathrm{Pd}$. The lack of Moire fringes which should arise due to lattice parameter or crystal structure mismatch, suggests that the Pd-rich shell remains metallic rather than being oxidized to PdO.

Finally, the presence of a core-shell structure with Pd segregating preferentially to the surface is also evidenced by the XPS data shown in Figure 3. While the uncalcined sample clearly shows the presence of both $\mathrm{Au}$ and $\mathrm{Pd}$, both spectra from the calcined sample and the subsequently reduced 
sample show only Pd. Since XPS is a highly surface sensitive technique, this suggests that the calcination process brings about surface segregation of $\mathrm{Pd}$.

This type of Pd segregation is unexpected since the Au-Pd system exhibits complete solid solubility, and any composition should yield a random distribution of both alloying constituents. However, previous evidence of this type of segregation has been observed in the Au-Pd bulk alloys when they have been calcined at elevated temperature in oxygen [3]. This phenomenon presumably occurs because of the lower bond energy of $\mathrm{Pd}-\mathrm{O}$ relative to Au-O. Furthermore, a subsequent reduction of the bulk alloy in $\mathrm{H}_{2}$ resulted in removal of the oxide layer without re-equilibration of the surface composition. The significance of having $\mathrm{Pd}$ enriched Au-Pd nanoparticles for the efficient production of $\mathrm{H}_{2} \mathrm{O}_{2}$ from $\mathrm{H}_{2}$ and $\mathrm{O}_{2}$ is currently being considered.

References

[1] L.W. Gosser and J. Schwartz, US Pat., 4772458, 1988.

[2] P.G. Kotula et al., Microscopy \& Microanalysis, 9, (2003), 1.

[3] L. Hilaire, P. Legare, Y. Holl, and G. Maire, Surface Science, 103, (1981), 125.

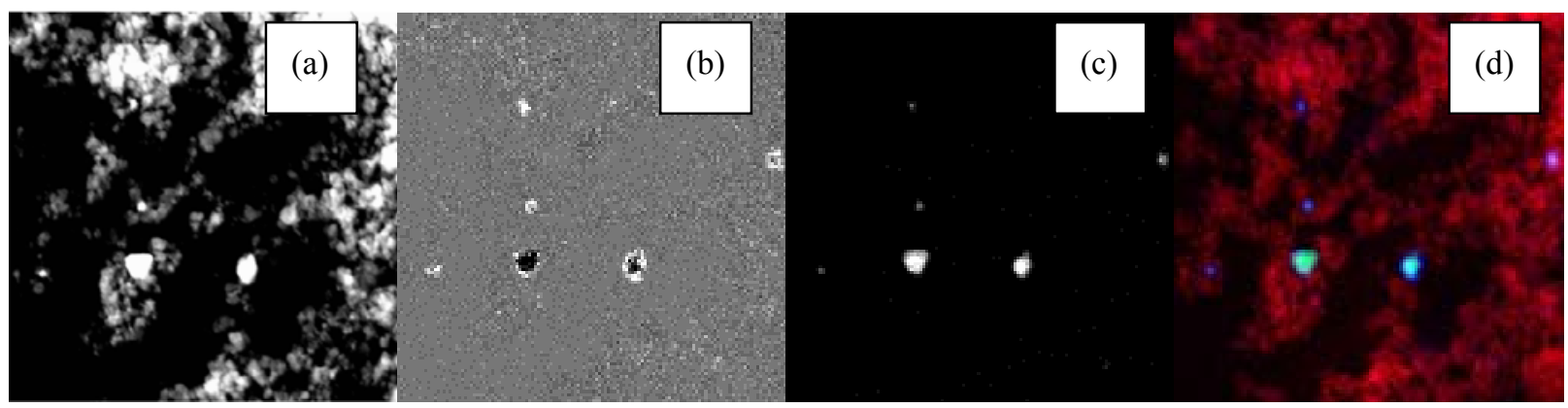

$400 \mathrm{~nm}$

FIG. 1. (a) HAADF image of 2.5\%Au-2.5\% Pd/Fe $\mathrm{O}_{3}$ (b) $\mathrm{Pd} \mathrm{L}_{1}$ STEM-XEDS map (c) Au $\mathrm{M}_{2}$ STEM-XEDS map (d) RGB image of three XEDS maps $($ red $=\mathrm{O}$, blue $=\mathrm{Pd}$, green $=\mathrm{Au})$

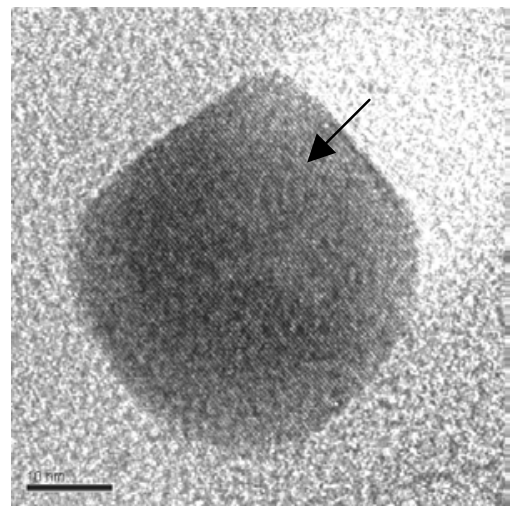

FIG. 2. HRTEM image of a single Au-Pd particle showing probable coreshell structure. The arrow indicates an abrupt contrast change.

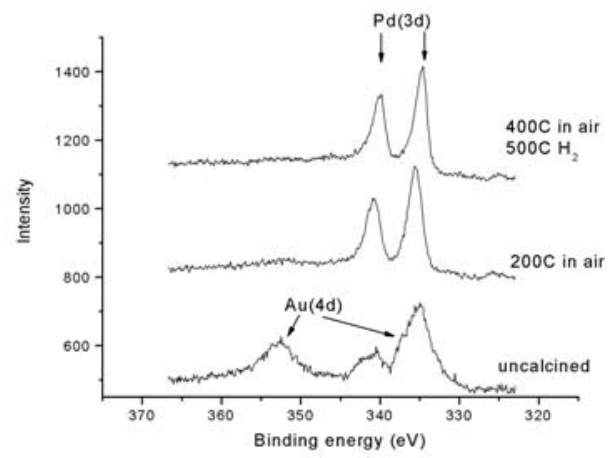

FIG. 3. XPS spectra from the $2.5 \% \mathrm{Au}-2.5 \% \mathrm{Pd} / \mathrm{Fe}_{2} \mathrm{O}_{3}$ catalysts showing the emergence of Pd surface segregation during calcination and subsequent reduction. 